\title{
A DESCENTRALIZAÇÃO E A INTERSETORIALIDADE NA POLÍTICA DE ASSISTÊNCIA SOCIAL
}

\author{
Adriana Giaqueto
}

\section{RESUMO}

Este artigo propõe refletir sobre os conceitos descentralização e intersetorialidade na Política de Assistência Social. Os conceitos de intersetorialidade e descentralização aproximam-se, na medida em que este último é compreendido como a transferência do poder de decisão para as instâncias mais próximas e permeáveis à influência dos cidadãos e o primeiro diz respeito ao atendimento das necessidades e expectativas desses mesmos cidadãos de forma integrada. Ambos os conceitos estão sujeitos a diferentes e até mesmo contraditórias interpretações. Buscamos enfatizar as compreensões voltadas para o efetivo controle organizado da sociedade civil sobre a ação governamental, pressupondo transferência de poder de decisão, de competências e de recursos, com garantias de canais de participação local. A operacionalização da política de assistência social em rede, com base no território, constitui um dos caminhos para superar a fragmentação na prática dessa política.

PALAVRAS-CHAVE: Política Social, Assistência Social, Descentralização, Intersetorialidade.

\section{INTRODUÇÃO}

O período pós-constitucional, no Brasil, está marcado por uma série de modificações profundas no campo social e da cidadania. Conhecida como Constituição Cidadã, a Constituição Federal de 1988 inova em aspectos essenciais, especialmente no que concerne à descentralização político-administrativa, alterando as normas e regras centralizadoras e distribuindo melhor as competências entre o Poder Central (União) e os poderes regionais (Estados) e locais (municípios). Também aumenta o estímulo à

\footnotetext{
${ }^{1}$ Professora Doutora do Departamento de Serviço Social da Faculdade de Ciências Humanas e Sociais da UNESP - Campus Franca/SP - Brasil. E-mail: marianadri@terra.com.br. 
maior participação das coletividades locais - sociedade civil organizada - e, portanto, ao processo de controle social.

No que tange à questão social especificamente, a Constituição Federal de 1988 introduziu um conceito novo: o conceito de seguridade social, incluindo o tripé saúde, previdência e assistência social. A noção de Seguridade supõe que os cidadãos tenham acesso a um conjunto de seguranças, que cubra, reduza ou previna situações de risco e de vulnerabilidades pessoais e sociais.

Hoje, a assistência Social conta com sua Lei Orgânica específica (Lei 8.742 de 07/12/1993), a LOAS (Lei Orgânica da Assistência Social). Trata-se, mais do que um texto legal, de um conjunto de ideias, de concepção e de direitos. A LOAS introduz uma nova forma de discutir a questão da Assistência Social, substituindo a visão centrada na caridade e no favor. É o instrumento que regulamenta os pressupostos constitucionais, ou seja, o conteúdo da Constituição Federal em seus artigos 203 e 204, que definem e garantem os direitos à assistência social.

Assim, a LOAS inova ao conferir à assistência social o status de política pública, direito do cidadão e dever do Estado. Inova também pela garantia da universalização dos direitos sociais e por introduzir o conceito dos mínimos sociais.

Os pressupostos constitucionais de assistência social também se concretizam por intermédio da Política Nacional de Assistência Social, que é um documento normatizador das ações de assistência social concebidas na LOAS. Esta, ao definir diretrizes, princípios, estratégias e formas de gestão da assistência social, constitui um instrumento de gestão que transforma em ações diretas os pressupostos legais, estabelece as competências e os fluxos entre as três esferas de governo. 


\section{A EFETIVAÇÃO DA ASSISTÊNCIA SOCIAL ENQUANTO POLÍtica PÚBLICA}

Em setembro de 2004, tivemos a aprovação da nova Política de Assistência Social, a qual contempla a proteção social básica e especial e as de segurança ${ }^{2}$ : de sobrevivência (de rendimento e autonomia); de acolhida; e, convívio ou vivência familiar (BRASIL, 2004, p. 31).

A proteção social básica é destinada a pessoas e famílias cujos vínculos familiares não foram rompidos. Realiza-se através de programas de acolhimento, convivência e socialização de acordo com a vulnerabilidade social apresentada. Estes serviços são desenvolvidos nos Centros de Referência de Assistência Social (CRAS) unidade pública estatal de base territorial, localizada em área de vulnerabilidade social, responsável pelo atendimento de um total de até 1000 (mil) famílias/ano. Tais unidades são responsáveis pela execução de serviços de proteção social, bem como a coordenação dos serviços socioassistenciais locais da área de abrangência.

Os serviços de proteção social especial são realizados nos Centros de Referência Especializados da Assistência Social (CREAS) e se destinam a famílias e indivíduos em situação de risco pessoal e social, por ocorrência de abandono, maus tratos físicos e, ou psíquicos, abuso sexual e outras situações de violação de direitos. Estão classificados em serviço de proteção social de média complexidade (famílias e indivíduos cujos vínculos não foram rompidos) e serviço de proteção social de alta complexidade (famílias e indivíduos sem referência e/ou situação de ameaça).

\footnotetext{
${ }^{2}$ De acordo com a PNAS segurança de rendimento não é uma compensação do salário mínimo inadequado, mas a garantia de que todos tenham uma forma monetária de garantir sua sobrevivência; Segurança de acolhida opera com a provisão de necessidades humanas que começa com os direitos à alimentação, ao vestuário, e ao abrigo, próprios à vida humana em sociedade, Ressalta-se que a conquista da autonomia na provisão destas necessidades e à orientação desta segurança; segurança da vivência familiar ou do convívio supõe a não aceitação de situações de reclusão, de situação de perda das relações. (BRASIL, 2004, p. 32)
} 
Em 15 de julho de 2005 foi aprovada a Norma Operacional Básica - NOB SUAS, que regulamenta a implantação do Sistema Único de Assistência Social, um sistema público não contributivo, descentralizado e participativo que tem como função a gestão da política de assistência no campo da proteção social brasileira.

Os serviços, programas, projetos e benefícios têm como foco prioritário a atenção às famílias, seus membros e indivíduos e o território como base de organização, que passam a ser definidos pelas funções que desempenham, pelo número de pessoas que deles necessitam e pela sua complexidade. Pressupõe, ainda, gestão compartilhada, cofinanciamento da política pelas três esferas de governo e definição clara das competências técnico-políticas da União, Estados, Distrito Federal e Municípios, com a participação da sociedade civil, e estes têm o papel efetivo na sua implantação e implementação.

O SUAS materializa o conteúdo da LOAS, define e organiza os elementos essenciais à execução da Política de Assistência Social, possibilitando a normatização dos padrões nos serviços, qualidade no atendimento, indicadores de avaliação e resultado, nomenclatura dos serviços e da rede socioassistencial e, ainda, os eixos estruturantes: matricialidade sociofamiliar, descentralização político-administrativa e territorialização, novas bases para a relação entre Estado e sociedade civil, financiamento, controle social, o desafio da participação popular/cidadão usuário, a política de recursos humanos, informação, o monitoramento e a avaliação.

A universalidade assume dois sentidos: $\mathrm{O}$ primeiro, de garantir o acesso aos direitos assistenciais a todo o universo demarcado pela LOAS. O segundo é o de articular a assistência às demais políticas sociais e econômicas, tendo como perspectiva a construção de um sistema de proteção social contínuo, sistemático, planejado, com recursos garantidos no orçamento público das três esferas governamentais (federal, 
estadual e municipal), com ações complementares entre si, evitando assim o paralelismo, a fragmentação e a dispersão de recursos. Enquanto política setorial, ela não tem a função de dar respostas cabais à pobreza. Seu horizonte deve ser o da sua inserção efetiva num projeto de desenvolvimento econômico e social, tanto local quanto nacional.

\section{A Descentralização e a Intersetorialidade enquanto princípios organizativos do} SUAS

Na relação entre as três esferas governamentais, o Governo Federal assume o papel de articulador da unidade nacional (LOAS, artigo 12). Os Estados assumem uma atribuição complementar à dos municípios: participar no financiamento dos auxílios natalidade e funeral, apoiar técnica e financeiramente os serviços, programas e projetos de enfrentamento da pobreza e atender às ações assistenciais de caráter emergencial (artigo13). Aos municípios e ao Distrito Federal coube a carga mais pesada: garantir o custeio e implementação dos benefícios eventuais (auxílio-natalidade e morte), implementar os projetos de enfrentamento à pobreza, atender às ações assistenciais de caráter emergencial e prestar os serviços assistenciais previstos na lei (artigos 14 e 15).

Esta distribuição de competências, se por um lado apresenta aspectos positivos, pode também conter riscos. O principal risco é a tendência de reduzir a descentralização a uma simples transferência de atribuições e responsabilidades aos Estados e, sobretudo, aos municípios, sem a correspondente transferência de recursos financeiros, humanos e materiais e, principalmente, sem dividir o poder político de tomada de decisão.

A Política de Assistência tem sua expressão em cada nível da federação na condição de comando único, na efetiva implantação e funcionamento de um conselho de composição paritária entre sociedade civil e governo, do Fundo, que centraliza os recursos na área, controlado pelo órgão gestor e fiscalizado pelo conselho, do Plano de 
Assistência que expressa a Política e suas interrelações com as demais políticas setoriais e ainda com a rede socioassistencial. Portanto, Conselho, Plano e Fundo são os elementos fundamentais de gestão da Política Pública de Assistência Social.

Segundo definições da nova versão da Política Nacional de Assistência Social (Brasil, 2004), o princípio da homogeneidade por segmentos na definição de prioridades de serviços, programas e projetos torna-se insuficiente frente às demandas de uma realidade marcada pela alta desigualdade social. Exige-se agregar ao conhecimento da realidade a dinâmica demográfica associada à dinâmica socioterritorial.

Dessa forma, uma maior descentralização, que recorte regiões homogêneas, costuma ser pré-requisito para ações integradas na perspectiva da intersetorialidade. Descentralização efetiva com transferência de poder de decisão, de competências e de recursos, e com autonomia das administrações dos microespaços na elaboração de diagnósticos sociais, diretrizes, metodologias, formulação, implementação, execução, monitoramento, avaliação e sistema de informação das ações definidas, com garantias de canais de participação local.

A descentralização é um dos pressupostos que tem informado as iniciativas de mudanças que ocorreram na gestão do setor social nas duas últimas décadas. Como um processo de transferência de poder dos níveis centrais para os periféricos das organizações, pretende colocar ao alcance dos diversos segmentos sociais o poder de decisão sobre as políticas sociais. Nesse sentido, constitui um meio de reestruturar o aparato estatal responsável pela gestão dessas políticas.

Essa discussão ocorreu nos países latinoamericanos, e em particular no Brasil, por ocasião da mudança dos regimes políticos autoritários, que se consolidaram com alto grau de centralização político-administrativa e exclusão social. Assim, a 
descentralização nesses países foi pautada, sobretudo, pela ótica política, expressando a necessidade de que se estabelecesse um contrato social entre Estado e sociedade civil.

A descentralização emerge integrada ao processo de superação de uma crise essencialmente política, que enfatiza a democratização e a participação, tornando-os, muitas vezes, como sinônimos. Apesar de a descentralização constituir um meio de viabilizar a participação, não garante, necessariamente, o acesso da população a quem decide. No entanto, estimula a dinâmica participativa, pois abre canais de comunicação entre usuários e as organizações descentralizadas, permitindo, no mínimo, que façam chegar suas necessidades a quem tem o poder de decidir.

A descentralização como um processo de transferência de poder determina a redistribuição do poder de decisão como resposta à centralização. Esse processo envolve mudanças na articulação entre Estado e sociedade, entre o poder público e a realidade social, e implica mudar a atuação do Estado, seu papel na gestão das políticas sociais.

A partir da Constituição de $1988^{3}$, o município foi reconhecido como ente federado e foram traçadas as diretrizes ${ }^{4}$ para a concretização do comando único das ações no âmbito federal, estadual e municipal com a participação da sociedade civil.

Na década de 1980, a descentralização do Estado aparece como exigência praticamente compulsória. De um lado esta exigência advém como forma de superar a crise fiscal que se instalou no interior do Estado, de outro, do avanço democrático da sociedade brasileira que pôs em questão o governo autoritário (SPOSATI; FALCÃO, 1990, p. 13)

\footnotetext{
${ }^{3}$ BRASIL, artigo 18.

${ }^{4}$ A descentralização político-administrativa para os estados do Distrito Federal, municípios e comando único das ações em cada esfera de governo; a participação da população, por meio de organizações representativas, na formulação das políticas e no controle das ações em todos os níveis; primazia da responsabilidade do Estado na coordenação da Política de Assistência Social em cada esfera de governo (BRASIL, 1993).
} 
A discussão sobre a descentralização pressupõe um controle das ações do Estado pela população, ou seja, alterações no núcleo do poder. Supõe uma reorganização de funções nas esferas federal, estadual e municipal a fim de haver uma distribuição de competências e responsabilidades, inclusive no financiamento das políticas públicas.

A realidade de cada município revela uma experiência específica e diversificada quanto à forma, tempo de organização, capacidades operacionais, dinâmicas e políticas próprias, e principalmente, a capacidade de organização e pressão da sociedade civil.

Portanto, a descentralização, como afirmam Sposati e Falcão (1990, p. 14):

[...] é associada com a reforma de Estado, isto é, uma nova relação entre Estado - Sociedade civil, Governo Povo, em que a autonomia das organizações governamentais locais venha a ser a possibilidade real de exercício do controle popular e exercício de sua capacidade de influência nas decisões.

A descentralização consiste em uma efetiva partilha de poder entre o governo e as coletividades locais. Está intimamente conectada com a reforma do Estado, ou seja, novas formas de relação povo-governo dentro do qual a autonomia das organizações locais proporciona o exercício de controle das coletividades locais e a possibilidade de influir nas decisões das várias instâncias de poder.

Em Jovchelovitch encontramos a distinção entre descentralização e desconcentração:

A descentralização consiste em uma efetiva partilha de poder entre o Estado e a coletividades locais, implica a autogestão local. Envolve uma redefinição da estrutura de poder no sistema governamental, que se realiza por meio do remanejamento de competências decisórias e executivas, assim como dos recursos necessários para financiá-las. Está hoje, portanto, intimamente conectada à reforma do Estado, ou seja, a novas formas de relação entre o Estado e a sociedade civil. É no 
redimensionamento da relação povo/governo que a autonomia das organizações locais proporciona o exercício do controle social e a possibilidade de influir nas decisões de várias instâncias de poder. [...] Precisamos ter cuidado para não falarmos de desconcentração, quando falamos de descentralização. A desconcentração pode ser entendida como a delegação de competência sem deslocamento de poder decisório ou como um processo de dispersão físico-territorial de instituições governamentais inicialmente localizadas de forma concentrada. [...] A descentralização, sim, envolve precipuamente uma questão de redistribuição de poder, de deslocamento de centros decisórios (2000, p. 33-47).

Ainda segundo a autora, os princípios fundamentais de descentralização são: mais flexibilidade, mais transparência, mais mecanismos de controle social. $^{5}$ Constituem aspectos importantes desse processo: a democratização do Estado; maior controle social sobre a administração pública de nível local; viabilização mais fácil de conversão de demandas sociais em programas e serviços; exercício do papel integrador das instituições municipais representativas de nível municipal.

Devemos estar atentos, entretanto, para uma concepção de descentralização de corte neoliberal, que a identifica como estratégia de redução do gasto público, visando combater a crise fiscal do Estado moderno. A descentralização, como estratégia de redução do gasto público, identifica-se com a seletividade do atendimento de demandas e necessidades e contrapõe-se às expectativas de universalização dos direitos sociais.

Além disso, no contexto do pensamento liberal, a descentralização poderá ser usada como mecanismo de transferência de encargos para os municípios sem a participação nos processos decisórios e no financiamento dos programas, pode ocorrer a

\footnotetext{
${ }^{5}$ Entendido como o controle organizado da Sociedade Civil sobre a ação governamental. Revista Serviço Social \& Saúde. UNICAMP Campinas, v. IX, n. 10, Dez. 2010
} 
privatização $^{6}$. Descentralização, em outra perspectiva, deverá significar divisão de poder, uma aproximação do Estado com a população e o respeito ao princípio da autonomia.

Jovchelovitch (2000, p. 38) trabalha também o conceito de municipalização, destacando que constituem seus princípios: a descentralização, o fortalecimento administrativo, a participação comunitária, o enfoque integrador da administração local. São condições para que haja municipalização: política tributária condizente, fim da legislação centralizadora, maior racionalidade nas ações, capacidade de gestão, planejamento participativo em nível local, participação popular efetiva e não apenas formal.

A municipalização, nesta linha de raciocínio, deve ser entendida como processo de levar os serviços mais próximos da população e não apenas repassar encargos para as prefeituras.

A descentralização e a municipalização, como consolidação democrática, estão sempre ligadas à participação e mostram que a força da cidadania está no município. É no município que as situações, de fato, acontecem. É no município que o cidadão constrói sua história. É onde ele pode fiscalizar e exercitar o controle social.

Entretanto, precisamos estar atentos para não mascarar as contradições: a descentralização não pode ser a centralização camuflada que, na verdade, só reparte o poder entre o chefe do executivo e seus assessores; e a municipalização não poder ser confundida com prefeiturização.

\footnotetext{
${ }^{6}$ No campo das ações sociais ocorre uma vertente da privatização através da produção de serviços indireta ou por convênio. Na área social a pobreza fica entendida como responsabilidade da sociedade civil, esta forma não supõe a descentralização porque não transfere a decisão, somente a produção de serviços (SPOSATI; FALCÃO, 1990, p. 126-45).
} 
Cabe ainda enfatizar a importância da participação real da sociedade civil e do governo (em seus três níveis) na discussão da Política Pública de Assistência Social. Por participação real entendemos aquela que dá origem ao novo, que leva as rupturas da ordem social vigente e é o oposto da participação formal.

Koga (2003) alerta que a transferência de um velho modelo centralizado de gestão das políticas públicas pode ocorrer facilmente no processo de descentralização. Pode-se repetir o modelo no âmbito mais restrito de gestão. Este risco embutido no processo de descentralização não é pequeno, tendo em vista a forte presença da cultura institucional brasileira marcada pela setorialização ou categorização no manejo das políticas públicas.

A própria intersetorialidade pode incorrer na armadilha de ser uma simples soma de programas e projetos, sem haver uma real estratégia conjunta de ação a partir do território. A lógica parte de um conhecimento comum sobre o lugar, contando com a participação dos sujeitos locais. Programas e projeto preestabelecidos ou elaborados em nível central, "de cima para baixo" podem ser pouco úteis na elaboração das políticas territoriais.

Municipalização, entretanto, não pode ser vista como "um remédio para todos os males”. A municipalização e a consolidação do poder local ainda são um desafio.

Ainda segundo Koga (2003, p. 39) o conceito mais amplo de municipalização pressupõe uma forma de poder mediador mais amplo que o prefeito e seus assessores. Poderíamos chamá-lo de "poder local”, e dele tomaria parte não só o Executivo, mas o Legislativo e organizações comunitárias, além dos conselhos setoriais, responsáveis pelo controle das políticas públicas em todos os níveis.

A municipalização, portanto, deve ser entendida não só como transferência de serviços e encargos, mas também de recursos e dotação orçamentárias suficientes. 
Temos de pensar no processo de descentralização, conhecer suas possibilidades e limites, pois o fortalecimento do poder local representa, sem dúvida, uma real contribuição para a democracia e a cidadania.

É necessário rompermos com as visões tradicionais e conservadoras a respeito da assistência para podermos avançar com as propostas novas, para tanto, é preciso ampliar os canais de comunicação, divulgação e troca de conhecimentos. Este é um trabalho urgente, embora seus frutos sejam percebidos mais em longo prazo.

A descentralização e a territorialização são pré-requisitos para o desenvolvimento de ações integradas com as demais políticas sociais na perspectiva da intersetorialidade, na busca por impactos verdadeiramente positivos na qualidade de vida dos cidadãos.

A intersetorialidade, por sua vez, proposta pelo SUAS, requer:

[...] mais do que a articulação ou a comunicação entre os diversos setores sociais, tais como saúde, educação, habitação, emprego e renda, saneamento e urbanização, por exemplo. Ela aponta para uma visão integrada do problema da exclusão, em uma perspectiva que situa a pobreza como um problema coletivo, algo que diz respeito ao conjunto da sociedade e que deve ser coletivamente enfrentado. (BRONZO; VEIGA, 2007, p. 11, grifo das autoras).

A efetivação do trabalho intersetorial requer a superação de inúmeros desafios: posicionamento e decisão política em favor ao redirecionamento da ação pública; estabelecimento de uma estrutura administrativa que viabilize a prática intersetorial; remanejamento de recursos financeiros e humanos para viabilizá-lo, criação de instrumentos de gestão apropriados ao novo arranjo; coordenação política e tecnicamente legitimada; criação de sistemas de informação interligados; 
estabelecimento de procedimentos de monitoramento e avaliação das ações integradas; dentre outros.

[...] tem-se a convicção de que essa perspectiva não é algo natural ou que ocorra de forma espontânea nas organizações públicas, mas que tem que ser ativamente construída, uma vez que decorre de deliberações claras e compartilhadas para introduzir as mudanças nos processos de trabalho no planejamento e na gestão das políticas públicas (BRONZO; VEIGA, 2007, p. 19).

Um dos entraves para a concretização do trabalho intersetorial, portanto, é a dificuldade do diálogo entre as diversas áreas de atendimento, que tem como uma de suas causas, a falta de informação sobre a Política de Assistência Social por parte dos outros órgãos e secretarias da prefeitura.

Além disto, a estrutura dos três níveis de governo no Brasil, como em outros países, é setorializada, significando uma organização que reflete a especialização de saberes, funções e modos de intervenção. Às políticas econômica e social correspondem uma segmentação de áreas de intervenção, bastante independentes, configurando uma organização de trabalho à qual corresponde uma estrutura organizacional verticalizada e setorializada. O Poder Executivo do Governo Federal é organizado por Ministérios, cada qual cuidando de uma política setorial - Ministério da Saúde, da Educação, da Previdência e outros. Isso se repete com as Secretarias de Estado que compõem a estrutura dos governos estaduais e chegam, do mesmo modo, ao governo municipal, com as respectivas Secretarias Municipais setoriais.

Essa lógica de operação do Estado responde melhor à especialização do saber e às corporações profissionais do que às necessidades e expectativas da população à que as ações e serviços se destinam. 
As estruturas setorializadas tendem a tratar o indivíduo e os problemas de forma fragmentada, com serviços executados solitariamente, embora as ações se dirijam à mesma criança, à mesma família, ao mesmo trabalhador e ocorram no mesmo espaço territorial e meio-ambiente. Conduzem a uma atuação desarticulada; o planejamento tenta articular as ações e serviços, mas a execução desarticula e perde de vista a integralidade do indivíduo e a interrelação dos problemas.

Os profissionais que atuam diretamente com a população percebem e denunciam, seguidamente, os efeitos da fragmentação das políticas sociais.

Contrapõe-se à setorialidade uma nova lógica que se refere basicamente à população, reconhecendo os indivíduos e grupos da população, considerando as suas condições peculiares de vida. As prioridades, nesse caso, são definidas a partir de problemas da população, cujo equacionamento envolve ações integradas de vários setores. Essa proposta supõe a articulação dos dois eixos: descentralização e intersetorialidade.

Os conceitos de intersetorialidade e descentralização aproximam-se, na medida em que este último é compreendido como a transferência do poder de decisão para as instâncias mais próximas e permeáveis à influência dos cidadãos e o primeiro diz respeito ao atendimento das necessidades e expectativas desses mesmos cidadãos de forma integrada.

Ambos devem considerar as condições territoriais que interagem com a organização social dos grupos populacionais.

Assim como descentralização não é sinônimo de democratização, mas um meio de viabilizá-la, a intersetorialidade não é um fim e nem irá, por si, promover o desenvolvimento e a inclusão social, mas é um fator de sua viabilização enquanto ação do Estado. 
Essa nova lógica deve viabilizar a identificação dos problemas e potencialidades dos grupos populacionais em relação a padrões de qualidade de vida, considerados a partir dos direitos de cidadania.

No município, como espaço definido territorial e socialmente, é que se concretiza a integração e a ação intersetorial. Essa interação pode ser construída através de um processo dinâmico entre os sujeitos, mediada por novos paradigmas, que devem informar a mudança das instituições sociais e de suas práticas. Esse processo de construção é também de aprendizagem e de determinação dos sujeitos, da sua consciência e dos seus direitos a uma vida de qualidade.

Uma lógica intersetorial de organização e atuação deve referir-se basicamente à população, considerando as suas formas e condições peculiares de organização. Assim, as prioridades não são setoriais, mas definidas a partir de problemas da população, cujo enfrentamento envolve ações integradas de vários setores.

\section{A viabilização da Descentralização e da Intersetorialidade na Política de} Assistência Social: o trabalho em rede

Outro desafio que se coloca no trabalho dentro da perspectiva da nova Política de Assistência Social, é o trabalho articulado, entre os profissionais, entre os CRAS, entre os CRAS e a administração da Secretaria de Assistência Social, entre as diversas Secretarias, entre os CRAS e as diversas instituições sociais.

Como vimos, a proposta de planejamento e intervenções intersetoriais envolve mudanças nas instituições sociais e suas práticas. Significa alterar a forma de articulação das ações em segmentos, para a universalização da proteção social, em prejuízo da setorialização. Implica também, em mudanças na cultura e nos valores da rede socioassistencial, das organizações gestoras das políticas sociais e das instâncias de 
participação. Para tanto, torna-se necessário constituir uma forma organizacional mais dinâmica, articulando as diversas instituições envolvidas.

De acordo com a Nova Política de Assistência Social, a operacionalização da política de assistência social em rede, com base no território, constitui um dos caminhos para superar a fragmentação dessa política. Trabalhar em rede, nessa concepção territorial significa ir além da simples adesão, pois há necessidade de se romper com velhos paradigmas, em que as práticas se construíram historicamente pautadas na segmentação, na fragmentação e na focalização, e olhar para a realidade, considerando os novos desafios colocados pela dimensão do cotidiano, que se apresenta sob múltiplas formatações, exigindo enfrentamento de forma integrada e articulada (BRASIL, 2004, p. 48)

O conceito de rede transformou-se, nas últimas décadas, em uma alternativa prática de organização, possibilitando processos capazes de responder às demandas de flexibilidade, conectividade e descentralização das esferas contemporâneas de atuação e articulação social.

A palavra rede vem do latim "retis" e significa entrelaçamento de fios com coberturas regulares que formam uma espécie de tecido. A partir da noção de entrelaçamento, malha e estrutura articulada, a palavra rede foi ganhando novos significados ao longo dos tempos, passando a ser empregada em diferentes situações.

O conceito de rede, embora incorporado pelas Ciências Sociais desde a década de 1940, vem se constituindo, nos anos recentes, num paradigma de análise bastante usado, com diversos significados.

O termo "rede" é utilizado tanto pela ciência, como conceito teórico ou metodológico, quanto por atores sociais que passaram a empregar essa noção para se referirem a determinado tipo de relação ou prática social. 
Apenas considerando-se as Ciências Humanas, já é grande a diversidade de uso do termo. A Geografia trata de redes técnicas, de produção, de redes territoriais e redes sociais urbanas amplas, sendo que esta última noção também é empregada pela Administração, pela Sociologia e pelos planejadores urbanos em geral. A Administração analisa as redes organizacionais, empresariais e de controle. No campo da Economia surge a noção de redes na esfera do mercado, do consumo, da produção. A antropologia faz uso dos conceitos de redes de vizinhança, de parentesco, de amizade. Da Sociologia vem a ideia de redes como articulação política, ideológica ou simbólica.

Além disso, as noções de rede utilizadas por outras ciências têm sido instrumentais para a análise das redes sociais. Da Biologia e da Ecologia é importada a ideia de rede como tecido social ou como rede energética. Das ciências da computação vem a noção de redes de informação.

Diferentes autores vêm combinando de maneira variada as contribuições disciplinares que lhes parecem válidas, tornando as abordagens cada vez mais multidisciplinares.

Scherer-Warren (1999) realiza uma síntese de algumas contribuições relevantes na análise de redes, situando-nos em relação a diferentes abordagens e utilizações metodológicas ou operacionais do conceito; discute a apropriação da noção de rede pelos movimentos sociais e atores coletivos e encaminha a indicação de alguns eixos metodológicos para sua análise pelas Ciências Sociais.

A autora destaca que do ponto de vista metodológico, das Ciências Humanas, é necessário analisar se as experiências empíricas de organização sob a forma de rede de movimento realizam o ideal proposto. Como o conceito propositivo de redes tem cunho ideológico e sentidos simbólicos diversos, cabe às Ciências Sociais interpretar tais sentidos e observar se na prática este ideal de democracia é efetivado. 
Organizar-se em torno de redes significa participar de uma visão da realidade que tenta superar a tradicional visão dicotômica de uma sociedade em dois nítidos grupos de conflito, opostos entre si. A ideia de rede implica admitir a complexidade do social, composto de setores e agrupamentos sociais heterogêneos, campos de múltiplas contradições, diversidades e discursos plurais, em que opera não apenas a lógica do conflito, mas também da cooperação e da solidariedade. (SCHERERWARREN, 1999, p. 50)

A rede surge da percepção conjunta dos problemas comuns e da possibilidade de resolvê-los de maneira integrada. Por isso que a linguagem da rede é uma linguagem de vínculos.

Uma estrutura em rede é uma alternativa à estrutura piramidal. Na estrutura em pirâmide as pessoas ou entidades organizam-se em níveis hierárquicos, que se superpõem, cada nível compreendendo menos integrantes do que o nível inferior. $\mathrm{O}$ conjunto se afunila a partir de uma base que pode ser mais ou menos ampla, para chegar a um topo no qual pode se encontrar um único integrante - o "chefe". A comunicação entre integrantes de diferentes níveis se faz de cima para baixo ou de baixo para cima, através dos níveis intermediários àqueles que se comunicam.

Esse tipo de organização é mais usual devido à influência da cultura e dos modos de agir dominantes. No confronto ou negociação entre organizações colocam-se sempre, frente a frente, seus responsáveis ou dirigentes, ou seja, os topos das respectivas pirâmides - numa perspectiva de poder versus contrapoder.

Whitaker fala sobre a estrutura em rede, em que seus integrantes se ligam horizontalmente a todos os demais, diretamente ou através dos que os cercam. "O conjunto resultante é como uma malha de múltiplos fios, que se pode espalhar 
indefinidamente para todos os lados, sem que nenhum dos seus nós possa ser considerado principal ou central, nem representante dos demais" (2000, p. 1).

As redes cultivam alguns valores, conceitos e práticas: igualdade, transparência, autonomia, respeito às identidades de cada integrante, horizontalidade, corresponsabilidade, engajamento, cooperação, liberdade de movimento (entradas e saídas).

A rede não é uma nova institucionalidade ou outra instância de poder; ela é uma possibilidade de estabelecer relações entre os diversos atores, preservando as diferenças. Isso remete à ideia de autonomia, de sistema e de complexidade.

Através de Whitaker (2000) podemos compreender, também, que embora as redes surjam como reação a problemas que se criam com as pirâmides, elas não pretendem necessariamente substituir ou se contrapor às estruturas piramidais. Há situações em que somente estas parecem ser possíveis ou desejáveis. Em outras, a estrutura em rede pode ser mais favorável à realização dos objetivos; e há ainda situações em que o melhor seria exatamente a combinação de ambas as estruturas.

O que a organização piramidal superpõe, de fato, são níveis de poder de decisão, e com ele a responsabilidade pela realização dos objetivos.

Na estrutura organizacional em rede - horizontal - todos têm o mesmo poder de decisão, porque decidem somente sobre sua própria ação e não sobre a dos outros. Não há dirigentes nem dirigidos, ou os que mandam mais e os que mandam menos. $\mathrm{E}$ todos têm o mesmo nível de responsabilidade - que se transforma em co-responsabilidade - na realização dos objetivos da rede (WHITAKER, 2000, p. 2).

Os elos que dão consistência a uma rede são as informações que transitam pelos canais que interligam seus integrantes. Informação é poder. Nas redes, o poder se 
desconcentra, por isso também a informação, que se distribui e se divulga para que todos tenham acesso ao poder que sua posse representa. Neste sentido, todos os membros devem ter acesso a todas as informações que nela circulem.

No trabalho em rede a realização de um objetivo depende mais do engajamento consciente de todos na ação, do que de disciplina e controle; tem que se contar é com a lealdade de cada um para com todos, baseada na corresponsabilidade. Uma rede não se move porque uma voz de comando a mobilizou, ela se move quando todos e cada um de seus membros começam, por decisão própria, a se mover.

\section{MAIS ALGUMAS CONSIDERAÇÕES}

A legislação configura-se uma valiosa ferramenta nas mãos daqueles que lutam pelos direitos sociais. No entanto, além da legislação, é preciso instalar o processo cultural. É outra luta dentro de uma luta maior, com avanços e recuos, com adesão e resistência. É um processo que não tem fim e que exige a vigilância constante.

Os mecanismos legais necessários à construção de um sistema descentralizado e participativo já existem. É preciso, agora, investir na sua efetivação. A consolidação da assistência social como política pública e direito social ainda exige o enfrentamento de muitos desafios.

As consequências da implementação do ideário neoliberal nas sociedades, que, como a brasileira, vivem os impasses da consolidação democrática, do frágil enraizamento da cidadania e das dificuldades históricas de sua universalização para a maioria da população, expressam-se pelo aumento das desigualdades, retração dos direitos sociais e trabalhistas, aprofundamento dos níveis de pobreza, agravamento da crise social. 
A descentralização emerge integrada ao processo de superação de uma crise essencialmente política, que enfatiza a democratização e a participação, tornando-os, muitas vezes, como sinônimos.

A transferência de um velho modelo centralizado de gestão das políticas públicas pode ocorrer facilmente no processo de descentralização. Pode-se repetir o modelo no âmbito mais restrito de gestão. Este risco embutido no processo de descentralização não é pequeno, tendo em vista a forte presença da cultura institucional brasileira marcada pela setorialização ou categorização no manejo das políticas públicas.

A própria intersetorialidade pode incorrer na armadilha de ser uma simples soma de programas e projetos, sem haver uma real estratégia conjunta de ação a partir do território. A lógica parte de um conhecimento comum sobre o lugar, contando com a participação dos sujeitos locais.

Devemos estar atentos para uma concepção de descentralização de corte neoliberal, que a identifica como estratégia de redução do gasto público, visando combater a crise fiscal do Estado moderno.

No contexto do pensamento liberal, a descentralização poderá ser usada como mecanismo de transferência de encargos para os municípios sem a participação nos processos decisórios e no financiamento dos programas, pode ocorrer a privatização.

A descentralização consiste, portanto, em uma efetiva partilha de poder entre o Estado e a coletividades locais, implica a autogestão local. Envolve uma redefinição da estrutura de poder no sistema governamental, que se realiza por meio do remanejamento de competências decisórias e executivas, assim como dos recursos necessários para financiá-las. Está intimamente relacionada à autonomia das 
organizações locais no exercício do controle social e a possibilidade de influir nas decisões de várias instâncias de poder.

Contrapõe-se à setorialidade uma nova lógica que se refere basicamente à população, reconhecendo os indivíduos e grupos da população, considerando as suas condições peculiares de vida. As prioridades, nesse caso, são definidas a partir de problemas da população, cujo equacionamento envolve ações integradas de vários setores.

Assim como descentralização não é sinônimo de democratização, mas um meio de viabilizá-la, a intersetorialidade não é um fim e nem irá, por si, promover a inclusão social, mas é um fator de sua viabilização.

A descentralização e a intersetorialidade configuram-se ainda, desafios quanto à gestão da Política de Assistência Social, no que diz respeito ao poder de decisão, ao financiamento da política, ao partilhamento não só dos serviços, mas do poder das decisões.

Essa perspectiva não é algo natural ou que ocorra de forma espontânea nas organizações públicas, mas tem que ser, muitas vezes, conquistada, ou até mesmo, construída.

Como vimos, de acordo com a nova Política de Assistência Social, a operacionalização da política de assistência social em rede, com base no território, constitui um dos caminhos para superar a desarticulação dos serviços.

A estrutura organizacional em rede, ao contrário da piramidal, é horizontal, cujo poder de decisão é distribuído igualmente entre todos os participantes do processo, assim como a responsabilidade, que se transforma em corresponsabilidade.

O exercício da liberdade, responsabilidade e democratização da informação, que a lógica das redes desenvolve, ajuda a mudar, nos seus participantes, os padrões 
introjetados pela cultura dominante. Caracteriza-se uma prática nova, de reeducação, um processo lento e gradativo.

É dentro dessa perspectiva que o SUAS pretende operacionalizar a Política de Assistência Social: em rede descentralizada, numa concepção territorial e intersetorial, buscando romper com a fragmentação na prática dessa política.

\begin{abstract}
This article proposes a reflection about the concepts of decentralization and intersectorality at the Politic of Social Assistance. The concepts of intersectorality and decentralization approximate themselves, as the last one is known as the transfer of power of decision for the closest and permeable instances to the influence of the citizen and the first one is about the meeting of the needs and expectation of this citizen in a seamlessly way. Both concepts are subject to different and even contradictory interpretations. We search to emphasize the comprehension directed to the effective organized control of the civil society on the governmental action, assuming the transfer of the power of decision, skills and resources with the guarantee of local participation.
\end{abstract}

KEYWORDS: Social Politic, Social Assistance, Decentralization, Intersectorality.

\title{
REFERÊNCIAS BIBLIOGRÁFICAS
}

BRASIL. Constituição (1988): Constituição da República Federativa do Brasil. Brasília/DF: Senado Federal, 1988.

. Lei $\mathrm{n}^{\circ}$ 8742, de 7 de setembro de 1993. Dispõe sobre a organização da

Assistência Social e dá outras providências. Diário Oficial da União: República Federativa do Brasil: Poder Legislativo, Brasília, DF, 8 dez. 1993.

, Ministério do Desenvolvimento Social e Combate à Fome e Secretaria

Nacional de Assistência Social. Política Nacional de Assistência Social. Brasília, 2004. 
BRONZO, C.; VEIGA, L. de. Intersetorialidade e políticas de superação da pobreza: desafios para a prática. Serviço Social \& Sociedade, São Paulo, ano 28, n. 92, p. 5 -21, nov., 2007.

JOVCHELOVITCH, M. O processo de descentralização no Brasil. In: FUNDAÇÃO ABRINQ PELOS DIREITOS DA CRIANÇA. Caderno Prefeito Criança: Políticas Públicas Municipais de Proteção Integral a Crianças e Adolescentes. São Paulo: Editora Raiz da Terra, 2000, p. 33-47.

KOGA, D. Medidas de cidades: entre territórios de vida e territórios vividos. São Paulo: Cortez, 2003, 303 p.

SCHERER-WARREN, I. Cidadania sem fronteiras: ações coletivas na era da globalização. São Paulo: HUCITEC, 1999, 95 p.

SPOSATI, A; FALCÃO, M. C. A Assistência Social Brasileira: descentralização e municipalização. São Paulo: EDUC, 1990, 118 p.

WHITAKER, F. Redes: conversando com Chico Whitaker. São Paulo: Ed. Paulinas, 2000,23 p. 